\title{
Identification of sensory neural hearing loss in very preterm infants by brainstem auditory evoked potentials
}

\author{
B C BRADFORD, J BAUDIN, M J CONWAY, J W P HAZELL, A L STEWART, AND \\ E O R REYNOLDS
}

Department of Paediatrics, University College London School of Medicine; Royal Ear Hospital, London; and Polytechnic of Central London

SUMMARY Brainstem auditory evoked potentials were recorded in 117 newborn infants of less than 33 weeks of gestation. The potentials were absent in 10 infants (bilaterally in eight and unilaterally in two) and present in 107. By 1 year of age nine of the 10 infants with absent brainstem auditory evoked potentials were shown to have sensory neural hearing loss and required hearing aids: the remaining infant had secretory otitis media. None of the 107 infants whose auditory evoked potentials were present were found to have sensory neural hearing loss but 13 had secretory otitis media. Measurement of brainstem auditory evoked potentials is an accurate method of identifying sensory neural hearing loss in very preterm infants.

Very preterm infants are at risk for sensory neural and conductive hearing loss. ${ }^{12}$ Early diagnosis is important so that causes can be explored and treatment started as soon as possible. Brainstem auditory evoked potentials have been used as an objective test of hearing in adults ${ }^{3}$ and children. ${ }^{4}$ These potentials can also be elicited in newborn infants, ${ }^{6}$ including those born well before term. ${ }^{78}$

This study was carried out to determine whether measurement of brainstem auditory evoked potentials in very preterm newborn infants predicted hearing status at 1 year of age.

\section{Infants studied and methods}

Infants studied. A total of 217 infants who had been born before 33 weeks of gestation were admitted to the Neonatal Unit of University College Hospital in the years 1980 to 1982 . Sixty $(28 \%)$ died and 35 $(16 \%)$ were sent back to their referring hospitals before testing of brainstem auditory evoked potentials could be carried out. The remaining 122 infants were tested. Their median gestational age was 30 weeks (range 24 to 32 weeks), and their median birthweight was $1285 \mathrm{~g}$ (range 600 to $2230 \mathrm{~g}$ ). Sixty nine were boys and 53 were girls. Seventy five were born in University College Hospital and 47 were referred from other hospitals. Five of the 122 infants died after testing had been done, leaving 117 long term survivors.

Measurements of brainstem auditory evoked potentials were first carried out when the infants were at a median postnatal age of 15 days ( 1 to 85 days) and a median gestation equivalent age (gestational age at birth plus postnatal age) of 32 weeks (range 26 to 42 weeks). All 122 infants were tested at a gestation equivalent age of at least 30 weeks and 79 were tested twice or more before discharge from the neonatal unit.

Measurement of brainstem auditory evoked potentials. Tests were performed when the infants were in a stable enough condition to tolerate gentle handling. They were usually being nursed in open or closed incubators and many were being mechanically ventilated or receiving oxygen in a head box.

A Medelec Amplaid Mk III system was used in 1980 and an Amplaid Mk IV system with a Texas Instruments Silent 733 terminal for data collection in 1981 and 1982. Details of the two systems are given in Table 1. Two standard silver/silver chloride electrodes were positioned over the mastoid processes and one at the vertex. The electrodes were held in place by Blutack and Netelast. ${ }^{9}$ The skin under the electrodes was very slightly abraded and electrode cream (Redux) was used to ensure good 
Table 1 Details of brainstem auditory evoked potentials measurement

\begin{tabular}{|c|c|c|}
\hline Year & 1980 & $1981-82$ \\
\hline Equipment & $\begin{array}{l}\text { Medelec Amplaid } \\
\text { Mk III }\end{array}$ & Amplaid Mk IV \\
\hline Earphones & TDH 39 & TDH 49 \\
\hline Stimulus type & $\begin{array}{l}\text { Wide band high } \\
\text { frequency rarefaction } \\
\text { click }\end{array}$ & $\begin{array}{l}\text { Wide band high } \\
\text { frequency rarefaction } \\
\text { click }\end{array}$ \\
\hline Duration & $100 \mu \mathrm{s}$ & $100 \mu \mathrm{s}$ \\
\hline Rate & $20 \mathrm{pps}$ & $21 \mathrm{pps}$ \\
\hline Intensity* & $\begin{array}{l}100 \mathrm{~dB} \text { PE SPL } \\
(80 \mathrm{~dB} \text { HL })\end{array}$ & $100 \mathrm{~dB}$ PE SPL \\
\hline \multicolumn{3}{|l|}{ Filter } \\
\hline $\begin{array}{l}\text { Type } \\
\text { Bandpass }\end{array}$ & $\begin{array}{l}6 \mathrm{~dB} / \text { octave roll off } \\
250-3200 \mathrm{~Hz}\end{array}$ & $\begin{array}{l}6 \mathrm{~dB} / \text { octave roll off } \\
100-2000 \mathrm{~Hz}\end{array}$ \\
\hline $\begin{array}{l}\text { Analysis time } \\
\text { Prestimulus }\end{array}$ & $20 \mathrm{~ms}$ & $30 \mathrm{~ms}$ \\
\hline $\begin{array}{l}\text { delay } \\
\text { Number of }\end{array}$ & $5 \mathrm{~ms}$ & $10 \mathrm{~ms}$ \\
\hline $\begin{array}{l}\text { responses } \\
\text { Data collection }\end{array}$ & 1024 & 2048 \\
\hline Data collection & UV sensitive paper & Digital cassette \\
\hline
\end{tabular}

${ }^{*}$ Calibrated using Bruel and Kjaer Type 2203 sound level meter and Bruel and Kjaer Type 152 artificial ear.

dB PE SPL=decibels peak equivalent sound pressure level.

$\mathrm{dB}$ HL $=$ decibels hearing level.

electrical contact: impedances between pairs of electrodes were $3 \mathrm{k} \Omega$ or less. The electrode leads were plaited to reduce the effects of electrical interference.

The measurements were made while the infant was sleeping, preferably lying prone. Artefact rejection was set at $\pm 2.5 \mu \mathrm{V}$ or $\pm 5 \mu \mathrm{V}$ to prevent the recording of muscle activity. Tests were made ipsilaterally and each ear was tested independently at least twice. If no response was obtained at the initial stimulus level (Table 1) the intensity was increased by 10 decibels $(\mathrm{dB})$ peak equivalent sound pressure level (PE SPL) and a second test was done. If no response was again obtained at least three tests were made on each ear at each stimulus level, and the infant was retested on at least one further occasion before discharge from hospital.

A response was judged to be 'present' when waves I, N, III, and V could be detected (see Figure), as compared with the averaged prestimulus trace, which was used as a reference. If no waves could be discriminated on repeated testing the response was judged to be 'absent'. Tests took about 30 to 60 minutes to complete.

Follow up. One hundred and twelve of the 117 infants attended a special developmental clinic so that their progress could be assessed as previously described: ${ }^{10}$ particular attention was paid to auditory behavioural responses and the onset of language development. For the purposes of follow up, the infants' ages were corrected for preterm birth by
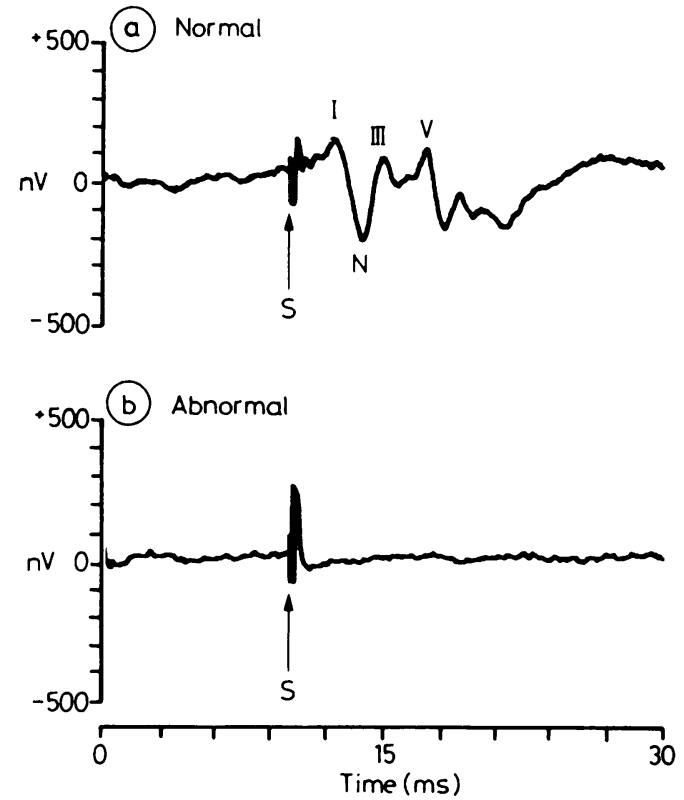

Figure (a) Normal brainstem auditory evoked potentials from an infant born at 29 weeks of gestation, weighing $1498 \mathrm{~g}$, and tested at 6 weeks of age. Waves I, III, and V are labelled as described by Jewett and Williston; ${ }^{15}$ $N=$ negative wave preceding wave III. ${ }^{\circ}$

(b) Absent brainstem auditory evoked potentials in an infant born at 32 weeks of gestation, weighing $1630 \mathrm{~g}$, and tested aged 3 weeks.

$\mathbf{S}=$ stimulus.

subtracting from their chronological age the number of weeks that they had been born before term. Measurement of brainstem auditory evoked potentials testing was repeated at 3 months of corrected age on 59 infants born in 1981 and 1982. At 6 months, postauricular myogenic response testing was carried out on 107 infants. ${ }^{11-13}$ Infants who failed to respond to the postauricular myogenic test at $76 \mathrm{~dB}$ PE SPL ( $60 \mathrm{~dB}$ hearing level) were retested within three months. A Griffiths baby test ${ }^{14}$ was done on 108 infants between the corrected ages of 47 and 91 (median 54) weeks by a psychologist who was unaware of the results of the neonatal brainstem auditory evoked potentials tests. Infants failing follow up auditory evoked potentials or postauricular myogenic response tests, or in whom there was any suspicion of hearing loss from developmental observations were referred to a neurootologist for otological investigation, acoustic impedance testing, behavioural distraction tests, and if necessary electrocochleography or measure- 
ment of brainstem auditory evoked potentials under general anaesthesia. Five of the 117 surviving infants emigrated aged 3 to 5 months, but information has been obtained about them, when aged 52 to 110 (median 77) weeks, from their parents and local doctors. All 117 survivors have been followed up for at least one year.

\section{Results}

In the neonatal period, $10(8 \cdot 2 \%)$ of the 122 infants had absent brainstem auditory evoked potentials; bilaterally in eight and unilaterally in two. Brief clinical details of these infants are given in Table 2. The potentials were present in the other 107 infants: equivocal results were never encountered. The results were confirmed in 58 of the 59 infants who were retested aged 3 months, including eight infants with absent responses. In one infant, potentials were initially present, but absent on retesting. Bilateral conductive loss due to secretory otitis media or 'glue ear' was diagnosed: after removal of the fluid bilateral responses were obtained.

The results of brainstem auditory evoked potentials testing in the newborn period are related in Table 3 to the results of postauricular myogenic

Table 2 Clinical details of 10 infants with absent neonatal brainstem auditory evoked potentials (BAEP)

\begin{tabular}{|c|c|c|c|c|c|c|c|}
\hline Infant & Sex & $\begin{array}{l}\text { Gestational } \\
\text { age (wks) }\end{array}$ & $\begin{array}{l}\text { Birthweight } \\
(g)\end{array}$ & Main neonatal diagnoses & Ultrasound brainscan & $\begin{array}{l}\text { BAEP } \\
\text { absent }\end{array}$ & SNHL aged 1 year \\
\hline 1 & $\mathbf{M}$ & 31 & 1735 & HMD, MV, Pn'x, renal failure & $\begin{array}{l}\text { PVH, post haemorrhagic } \\
\text { hydrocephalus }\end{array}$ & $R+L$ & $\mathrm{R}+\mathrm{L}$ \\
\hline 2 & $\mathrm{~F}$ & 31 & 1314 & HMD, MV & $\begin{array}{l}\text { PVH, mild ventricular } \\
\text { distension }\end{array}$ & $\mathrm{R}+\mathrm{L}$ & $\mathbf{R}+\mathbf{L}$ \\
\hline 3 & $\mathbf{M}$ & 28 & 995 & Down's syndrome & Normal & $\mathbf{R}$ & $\mathrm{R}$ (+bilateral SOM) \\
\hline 4 & $\mathbf{M}$ & 32 & 1630 & HMD, MV, Pn'x & $\begin{array}{l}\text { PVH, post haemorrhagic } \\
\text { hydrocephalus }\end{array}$ & $\mathrm{R}+\mathrm{L}$ & $\mathrm{R}+\mathrm{L}$ \\
\hline 5 & $\mathbf{M}$ & 27 & 1196 & HMD, MV, BPD & $\begin{array}{l}\text { Generalised cerebral } \\
\text { atrophy }\end{array}$ & $\mathrm{R}+\mathrm{L}$ & $R+L$ \\
\hline 6 & $\mathbf{F}$ & 30 & 1268 & $\begin{array}{l}\text { Klippel-Feil syndrome, } \\
\text { HMD, MV }\end{array}$ & PVH & $\mathrm{L}$ & $\mathrm{L}(+$ bilateral SOM) \\
\hline 7 & $\mathbf{M}$ & 29 & 940 & HMD, MV, BPD & Normal & $\mathrm{R}+\mathrm{L}$ & $\mathrm{R}+\mathrm{L}$ \\
\hline 8 & $\mathrm{~F}$ & 26 & 955 & MV & $\begin{array}{l}\text { PVH, mild ventricular } \\
\text { distension }\end{array}$ & $\mathbf{R}+\mathbf{L}$ & $\mathrm{R}+\mathrm{L}$ \\
\hline 9 & $\mathbf{M}$ & 28 & 859 & $\begin{array}{l}\text { MV, congenital abnormalities, } \\
\text { thrombocytopenia }\end{array}$ & $\begin{array}{l}\text { PVH, small thalamic } \\
\text { haemorrhage }\end{array}$ & $\mathbf{R}+\mathbf{L}$ & $\mathrm{R}+\mathrm{L}$ \\
\hline 10 & $\mathbf{M}$ & 30 & 1277 & HMD, MV & Normal & $\mathrm{R}+\mathrm{L}$ & (bilateral SOM) \\
\hline
\end{tabular}

SNHL=sensory neural hearing loss; SOM=secretory otitis media; $\mathrm{R}=$ right ear; $\mathrm{L}=$ left ear; $\mathrm{HMD}=$ hyaline membrane disease; $\mathrm{MV}=$ mechanical ventilation Pn'x=pneumothorax; $B P D=$ bronchopulmonary dysplasia. Ultrasound scans were performed and interpreted as described by Stewart et al. PVH=periventricular haemorrhage: the only infant with intraparenchymal extension was infant 1.

Maximum total plasma bilirubin concentrations in the 10 infants ranged from 180 to 348 (mean 228$) \mu \mathrm{mol} / \mathrm{l}(10 \cdot 5 \mathrm{to} 20 \cdot 3$ (mean $13 \cdot 3$ ) $\mathrm{mg} / 100 \mathrm{ml}$ ); and for gentamicin (trough values), 1.5 to $4 \cdot 0$ (mean $2 \cdot 5) \mu \mathrm{g} / \mathrm{ml}$. All infants except infant 10 had recurrent apnoeic spells.

Table 3 Relation between brainstem auditory evoked potentials (BAEP) response in the neonatal period, the results of postauricular myogenic response (PAM) tests, the Griffiths baby test, and hearing status at 1 year of age in 117 infants

\begin{tabular}{|c|c|c|c|c|c|c|c|}
\hline \multirow[t]{2}{*}{$B A E P$ response } & \multirow[t]{2}{*}{ PAM test } & \multirow[t]{2}{*}{ No } & \multirow{2}{*}{$\begin{array}{l}\text { Griffiths test } \\
\text { (a) Overall } G Q \\
\text { (b) Hearing and } \\
\text { speech subscale }\end{array}$} & \multirow[t]{2}{*}{ No } & \multicolumn{3}{|c|}{ Hearing status } \\
\hline & & & & & $\begin{array}{l}\text { Normal } \\
\text { No }\end{array}$ & $\begin{array}{l}\text { SOM } \\
\text { (Conductive } \\
\text { loss) } \\
\text { No }\end{array}$ & $S N H L$ \\
\hline \multirow{2}{*}{ Absent $(n=10)$} & Pass & 0 & - & 0 & 0 & 0 & 0 \\
\hline & Not tested & 2 & $\begin{array}{l}\text { (a) } 74,97 \\
\text { (b) } 32,81\end{array}$ & 2 & 0 & 0 & 2 \\
\hline \multirow{3}{*}{ Present $(n=107)$} & Pass & 65 & $\begin{array}{l}\text { (a) } 105(57-137) \\
\text { (b) } 102(59-139)\end{array}$ & 65 & 65 & 0 & 0 \\
\hline & Fail & 36 & $\begin{array}{l}\text { (a) } 101(63-115) \\
\text { (b) } 96(59-132)\end{array}$ & 34 & 25 & 11 & 0 \\
\hline & Not tested & 6 & $\begin{array}{l}\text { (a) } 100(88-103) \\
\text { (b) } 110(98-117)\end{array}$ & 3 & 4 & 2 & 0 \\
\hline
\end{tabular}

* = Median (range); $\dagger=$ two infants also had secretory otitis media

SOM=secretory otitis media; SNHL=sensory neural hearing loss. 
response tests, Griffiths tests (overall GQ, and the hearing and speech subscale), and hearing status assigned between 12 and 18 months of age. Two of the 10 infants with absent potentials did not undergo postauricular myogenic response testing because they had already been referred for investigation and found to have sensory neural hearing loss. The other eight underwent postauricular myogenic response testing and all failed: seven proved to have sensory neural hearing loss (together with secretory otitis media in two); the eighth had secretory otitis media requiring surgical intervention and, presumably, conductive loss. In accordance with the neonatal brainstem auditory evoked potential results, sensory neural hearing loss was bilateral in seven and unilateral in two. All nine infants required hearing aids. Of the 107 infants whose auditory evoked potentials were present, 101 had a postauricular myogenic response test and 36 failed. All 36 had audiological and otological investigations: 25 were judged to have normal hearing at 1 year of age and the other 11 had conductive loss due to secretory otitis media.

\section{Discussion}

Brainstem auditory evoked potentials are far field reflections of the electrical activity which occurs in the brain in response to an acoustic signal, ${ }^{8}$ and which can be extracted from the electroencephalograph by filtering and averaging. ${ }^{15}$ The response, described originally by Sohmer and Feinmesser in $1967,{ }^{16}$ consists in the adult of a series of seven waves of neural activity with latencies of less than 9 msecs, labelled I-VII by Jewett and Williston. ${ }^{15}$ Individual waves have been linked with specific generator sites in the auditory pathway, ${ }^{17} 18$ although more recent studies have indicated that the origin of the waves may not be so precisely located. ${ }^{19}{ }^{20}$ In the normal newborn infant, waves $I$, $\mathrm{N}$, III, and $\mathrm{V}$ are regularly elicited ${ }^{5-7}$ and the response provides an objective measure of the integrity of the auditory pathways. The response does not seem to be state dependent, ${ }^{21}$ and can be obtained in the quietly sleeping infant without sedation. Except in one continuing study of 'high risk' infants, giving early results similar to our own, ${ }^{22}$ and another in which infants with normal responses were apparently not followed up, ${ }^{23}$ previous investigators have generally defined abnormalities of brainstem auditory evoked potentials in terms of waveform, latency, and threshold. ${ }^{24-28} \mathrm{By}$ analogy with studies in older children and adults these measures have been assumed to indicate impairment of hearing. Measures of latency, however, are known to change with increasing age, 6726272930 so interpretation is difficult or impossible in the absence of clearly defined gestation equivalent age-dependent norms. Also, both latency and threshold may be affected by fluid or other extraneous material in the middle ear or in the external auditory canal. ${ }^{31}{ }^{32}$ In our experience this may cause particular problems in the interpretation of negative results in very preterm infants tested before 30 weeks of gestation equivalent age. Furthermore, preterm infants, particularly those who have been mechanically ventilated, are known to be susceptible to effusions in the middle ear that may recur intermittently during the first year of life ${ }^{33}$ It is therefore not surprising that poor correlations have been reported ${ }^{24}{ }^{28}$ between 'abnormal' brainstem auditory evoked potentials in newborn infants and later hearing status.

In this study, abnormality of potentials was rigorously defined as no response to a stimulus level of 100 or $110 \mathrm{db}$ PE SPL. This level was above the background noise level of 60 to $70 \mathrm{~dB}$ SPL. All the infants were tested after they had reached a gestation equivalent age of at least 30 weeks. Steps taken to enhance the precision of detection of potentials included ensuring good electrode contact with the scalp, setting the level of artefact rejection low enough to exclude potentials related to small movements of the eyes and face, and judging the presence or absence of a response by comparison with a reference trace.

Having adopted these simple methods, a strong association was found between the results of testing of brainstem auditory evoked potentials in the neonatal period and hearing status at 1 year of age. Nine of the 10 infants with absent potentials had sensory neural hearing loss requiring hearing aids, and the other infant had secretory otitis media. Conversely, none of the 107 infants whose potentials were present were found to have sensory neural hearing loss, though conductive loss due to secretory otitis media was detected in 13 .

We conclude that measurement of brainstem auditory evoked potentials in very preterm infants is a comparatively simple and practical procedure which can be carried out in the neonatal intensive care unit and which seems to predict with great accuracy the presence or absence of sensory neural hearing loss severe enough to require hearing aids. Longer follow up is required, however, before final conclusions can be reached. All the children in this study are remaining under surveillance so that the relation between the results of brainstem auditory evoked potential testing in the newborn period and pure tone audiograms at the age of 4 years can be determined. By contrast with sensory neural hearing loss, secretory otitis media is an intermittent condi- 
tion, so it is not surprising that potentials were present in some newborn infants who were later shown to have this. This emphasises the need for repeated tests of hearing in very preterm infants as they grow.

We thank the staff of the Neonatal Unit and the Children's Outpatient Department, Mrs J Baldwyn, Miss J Butler, Mrs D Collins, Dr A M de L Costello, Mrs G Harris, Dr P L Hope, Dr A P Lipscomb, Miss S MacDonald, Ms E A Meadows, Dr L Roberts, Dr R J Thorburn, and Miss J Townsend for their help. This work was supported by the Medical Research Council.

\section{References}

I Abramovitch SJ, Gregory S, Slemick M, Stewart A. Hearing loss in very low birthweight infants treated with neonatal intensive care. Arch Dis Child 1979;54:421-6.

2 Hope PL, Hazell JWP, Stewart AL. Sensorineural hearing loss in the very low birthweight survivor. In: Proceedings of the scientific meeting of the British Association of Audiological Physicians and Community Paediatric Group. Manchester: University of Manchester, 1983;23-37.

3 Jerger J, Mauldin L. Prediction of sensorineural hearing level from the brainstem evoked response. Arch Otolaryngol 1978; 104:456-61.

${ }^{4}$ Mokotoff B, Schulman-Galambos C, Galambos R. Brain stem auditory evoked responses in children. Arch Otolaryngol 1977; 103:38-43.

${ }^{5}$ Hecox K, Galambos R. Brainstem auditory evoked responses in human infants and adults. Arch Otolaryngol 1974:99:30-3.

${ }^{6}$ Salamy A, McKean CM. Postnatal development of human brainstem potentials during the first year of life. Electroencephalogr Clin Neurophysiol 1976;40:418-26.

7 Shulman-Galambos C, Galambos R. Brainstem auditory evoked responses in premature infants. $J$ Speech Hear Res 1975;18:456-65.

${ }^{8}$ Hazell JWP, Sheldrake JB, Reynolds EOR. Auditory evoked potentials in the newborn. In: Rolfe P, ed. Fetal and neonatal physiological measurements. Tunbridge Wells: Pitman Medical, 1980:198-205.

${ }^{9}$ Viniker DA, Bromley IE, Maynard DE. Monitoring the neonate with the cerebral function monitor. In: Rolfe P, ed. Fetal and neonatal physiological measurements. Tunbridge Wells: Pitman Medical, 1980:297-306.

10 Stewart AL, Thorburn RJ, Hope PL, Goldsmith M, Lipscomb AP, Reynolds EOR. Ultrasound appearance of the brain in very preterm infants and neurodevelopmental outcome at 18 months of age. Arch Dis Child 1983;58:598-604.

1 Fraser JG, Conway MJ, Keene MH, Hazell JWP. The post auricular myogenic response: a new instrument which simplifies its detection by machine scoring. J Laryngol Otol 1978;92: 293-303.

12 Flood LM, Fraser JG, Conway M, Stewart A. The assessment of hearing in infancy using the post-auricular myogenic response. Br J Audiol 1982;16:211-4.

${ }^{13}$ Holmes N, Conway MJ, Flood L, Fraser JG, Stewart A. Language development in a group of very low-birth-weight children whose postauricular myogenic response was tested in infancy. Pediatrics 1983;71:257-61.
${ }^{14}$ Griffiths R. The abilities of babies. London: University of London Press, 1954

15 Jewett DL, Williston JS. Auditory evoked far fields averaged from the scalp of humans. Brain 1971;94:681-96.

${ }^{16}$ Sohmer H, Feinmesser M. Cochlear action potentials recorded from the external car in man. Ann Otol Rhinol Laryngol 1967;76:427-35.

${ }^{17}$ Lev A, Sohmer H. Sources of averaged neural responses recorded in animal and human subjects during cochlear audiometry (electrocochleography). Archiv für klinische und experimentelle ohvren-nasen- und kehlkapfheilkunde (Berlin) 1972;201:79-90.

${ }^{18}$ Buchwald JS, Huang CM. Far-field acoustic responses: origins in the cat. Science 1975;189:382-4.

19 Achor LJ, Starr A. Auditory brain stem responses in the cat. I. Intracranial and extracranial recordings. Electroencephalogr Clin Neurophysiol 1980;48:154-73.

21) Achor LJ, Starr A. Auditory brain stem responses in the cat. II. Effects of lesions. Electroencephalogr Clin Neurophysiol 1980; 40:174-90.

21 Amadeo M, Shagass C. Brief latency click evoked potentials during waking and sleep. Psychophysiology 1973;10:244-50.

22 Alberti PW, Hyde ML, Riko K, Corbin H, Abramovitch S. An evaluation of BERA for hearing screening in high risk neonates. Laryngoscope 1983;93:1115-21.

23 Schulman-Galambos C, Galambos R. Brainstem evoked response audiometry in newborn hearing screening. Arch Otolaryngol 1979;105:86-90.

${ }^{24}$ Cox LC, Hack M, Metz DA. Longitudinal ABR in the NICU infant. Int J Pediatr Otorhinolaryngol 1982;4:225-31.

${ }^{25}$ Despland PA, Galambos R. The auditory brain stem response (ABR) is a useful diagnostic tool in the intensive care nursery. Pediatr Res 1980;14:154-8.

26 Fawer C-L, Dubowitz LMS. Auditory brainstem response in neurologically normal preterm and fullterm infants. Neuropediatrics 1982:13:200-6.

${ }^{27}$ Marshall RE, Reichart TJ, Kerley SM. Davics H. Auditory function in newborn intensive care unit patients revealed by auditory brain-stem potentials. Pediatrics 1980;96:731-5.

${ }^{28}$ Roberts JL, Davis H, Phon GL, Reichart TJ, Sturtevant EM, Marshall RE. Auditory brainstem responses in preterm neonates. Maturation and follow up. Pediatrics 1982;101:257-63.

${ }^{29}$ Goldstein PJ, Krumholz A. Felix JK, Shannon D, Carr RF. Brainstem evoked responses in neonates. Am J Obstet Gynecol 1979;135:622-8.

30) Starr A, Amlie RN, Martin WH, Sanders S. Development of auditory function in newborn infants revealed by brainstem potentials. Pediatrics 1977;60:831-9.

${ }^{31}$ Mendelson T, Salamy A, Lenoir M, McKean C. Brainstem evoked potential findings in children with otitis media. Arch Otolaryngol 1979;105:17-20.

32 Woods JR. Plessinger DS, Mack BS. Fetal auditory brainstem evoked response (ABR). Pediatr Res 1983;18:83-5.

33 Balkany TJ, Berman SA, Simmons MA, Jajek BW. Middle ear effusions in neonates. Laryngoscope 1978;88:398-405.

Correspondence to Miss B C Bradford, Department of Paediatrics, University College London School of Medicine, Rayne Institute, 5 University Street, London WC1E 6JJ.

Received 26 October 1984 